\title{
The association between basal body temperature, sexual swelling and urinary gonadal hormone levels in the menstrual cycle of the chimpanzee
}

\author{
C. E. Graham, H. Warner, J. Misener, D. C. Collins and J. R. K. Preedy \\ Yerkes Primate Center and Department of Medicine, Emory University, \\ Atlanta, Georgia 30322, U.S.A.
}

\begin{abstract}
Summary. Basal body temperature (BBT) was measured continuously by radiotelemetry throughout 14 chimpanzee menstrual cycles and correlated with daily observations of the sexual skin swelling. A biphasic BBT shift from a pre-nadir mean of $36.12^{\circ} \mathrm{C}$ to a post-nadir mean of $36.67^{\circ} \mathrm{C}$ was observed in 12 cycles. The temperature nadir showed a close temporal relationship with detumescence of the sexual skin swelling (an early luteal event), but the rate of temperature rise after the nadir was variable.

In 3 normal cycles studied, the temperature nadir occurred the day after a urinary oestrone peak, but there was no consistent temporal association between BBT rise and pregnanediol increment. Progesterone secretion is therefore probably not the sole determinant of the $\mathrm{BBT}$ shift; the changing oestrogen/progestin ratio may be the more important factor regulating body temperature during the luteal phase.
\end{abstract}

\section{Introduction}

The biphasic shift of basal body temperature (BBT) from descending temperatures at midcycle to increasing temperature in the luteal phase has been widely used as a retrospective indicator of the time of ovulation. The rise in temperature after the nadir is generally agreed to be due to a thermogenic effect of progesterone secreted by the corpus luteum (Davis \& Fugo, 1948; Israel \& Schneller, 1950; Tausk \& de Visser, 1971). Nevertheless, correlations of temperature change with estimates of ovulation based on progesterone-dependent events such as luteal and endometrial development and pregnanediol excretion have yielded variable results (Buxton \& Engle, 1950; Kalant, Pattee, Simpson, \& Hendelman, 1956). Such variability might be due to differences in progesterone secretion (Kalant et al., 1956), responsiveness of progesterone-dependent events, including the temperature elevation, or to sampling errors arising from use of single daily temperature determinations. Moreover, oestrogens are also known to affect body temperature (Davis \& Fugo, 1948).

The chimpanzee is an excellent model for the study of the human menstrual cycle; the hormonal changes are similar and observation of the sexual skin indicates periods of oestrogen secretion (swelling) and the beginning of the luteal phase (regression) (Graham, Collins, Robinson \& Preedy, 1972; Graham, Keeling, Chapman, Cummins \& Haynie, 1973; Graham, 1973).

In the present study we have measured BBT throughout 14 chimpanzee menstrual cycles. We used a radiotelemetry system to permit continuous nocturnal monitoring, to reduce the variability inherent in single daily temperature determinations and to avoid the alteration in body temperature associated with the anaesthesia needed for conventional temperature determinations (Morrison, 1962). BBT was correlated with the sexual swelling, and also with the levels of urinary oestrone and pregnanediol in some cycles.

\section{Materials and Methods}

Three adult female chimpanzees (Pan troglodytes) of reproductive age (19-25 years) and weighing $39 \cdot 3-60 \cdot 8 \mathrm{~kg}$ were used. Menstruation had been regular: the incidence of menstrual bleeding and the size of the perivaginal sexual swelling was estimated and recorded daily on an arbitrary scale of 0-4. 


\section{Temperature measurements}

Temperature transmitters were implanted in the three animals. The telemetry system has been described elsewhere (Warner \& Graham, 1975). The transmitter was encased in medical-grade silicone rubber and in the present study was implanted between the interior and exterior oblique muscle of the abdomen, lateral to the midline and close to the rib cage (12 cases), in the abdominal midline beneath the subcutaneous fat ( 2 cases), or in a dorsal subcutaneous location, inferior to the clavicle (1 case). The signal from the transmitter was a 94-120 MHz FM carrier, modulated to generate a pair of pulses which recurred at an interval inversely proportional to body temperatures; the signal was detected by a modified FM entertainment-type receiver, and converted by a demodulator into a DC voltage, recorded on a Rustrak paper chart recorder continuously operating at $0.25 \mathrm{in} / \mathrm{h}$. The absolute accuracy of the system was $\pm 0 \cdot 1^{\circ} \mathrm{C}$, determined by calibrating the transmitter in a water bath at $35^{\circ} \mathrm{C}$ and $40^{\circ} \mathrm{C}$ against a mercury thermometer certified by the National Bureau of Standards. Battery life of the transmitters permitted monitoring of subjects for periods of $90-130$ days without interruption.

Temperature data were recorded by taking readings from the chart paper at hourly intervals between 20.00 and $06.00 \mathrm{~h}$ when the temperature was usually nearly basal. The temperature shift was defined as a nadir followed by a rise exceeding the mean values during the follicular phase. The first day of the temperature rise was defined as the first day on which the temperature exceeded the nadir by $0.3^{\circ} \mathrm{C}$.

\section{Urinary steroid analysis}

Twenty-four hour urine samples were collected at $5^{\circ} \mathrm{C}$ during 4 menstrual cycles and were stored at $-20^{\circ} \mathrm{C}$ until analysed by methods previously described in detail (Graham et al., 1972). Approximately $5000 \mathrm{ct} / \mathrm{min}$ each of $\left[1,2,6,7 \beta-{ }^{3} \mathrm{H}\right]$ pregnanediol $\left(\mathrm{sp}\right.$. act. $85 \mathrm{Ci} / \mathrm{mmol}$ ) and $\left[6,7-{ }^{3} \mathrm{H}\right]$ oestrone (sp. act. $52 \mathrm{Ci} / \mathrm{mmol}$ ) were added as internal standards to a $10 \%$ volume of each 24 -h urine sample. The samples were refluxed with $\mathrm{HCl}$ and then extracted with ether. The dried ether extract was partitioned between toluene and $1 \mathrm{~N}$-aqueous $\mathrm{NaOH}$. The toluene extract was used for measurement of pregnanediol ( $5 \beta$-pregnan-3 $\alpha, 20 \alpha$-diol) using gas chromatography as previously described (Graham et al., 1972). The recovery of pregnanediol was $42 \pm 1 \cdot 2 \%(\mathrm{~N}=30)$. The sensitivity of the assay was $80 \mu \mathrm{g}$ and the coefficient of variation was $4.2 \%$ for a control value of $972 \mu \mathrm{g}$. The $\mathrm{NaOH}$ solution was adjusted to $\mathrm{pH} 9$ and extracted with ether. The ether extract was chromatographed using the celite partition system described by Preedy \& Aitken (1961). Fractions were collected and analysed for radioactivity and mass of oestrone (3-hydroxyoestra-1,3,5,(10)-trien-17-one) as previously described (Graham et al., 1972). The recovery of oestrone was $63 \pm 2 \cdot 1 \%(\mathrm{~N}=30)$ and this value was used in the calculations. The sensitivity of the assay was $1.0 \mu \mathrm{g}$ and the coefficient of variation was $5.8 \%$ for a control value of $18 \cdot 3 \mu \mathrm{g}$.

\section{Results}

Chimpanzees A and B both showed the anticipated circadian rhythm in BBT with a stable nocturnal plateau, as previously reported (Warner \& Graham, 1975). Chimpanzee C showed a reversed circadian rhythm, with a nocturnal temperature rise. The possibility of a polarity error in the telemetry system in Chimpanzee $\mathrm{C}$ was excluded, and an apparently normal biphasic shift was observed in this animal.

Temperature data were obtained from 14 menstrual cycles. In 12 of the cycles a clear biphasic shift in BBT occurred, and the data from these 12 cycles were pooled and normalized to the nadir (Text-fig. 1). The mean pre-nadir temperature for all cycles analysed was $36.50^{\circ} \mathrm{C}$ and the mean nadir was $36.12^{\circ} \mathrm{C}$. By $48 \mathrm{~h}$ after the nadir, mean temperature had risen to $36.48^{\circ} \mathrm{C}$, and it plateaued in the range of $36 \cdot 74-36.93^{\circ} \mathrm{C}$ on Day +4 , before a decline began on Day +12 . The mean post-nadir temperature was $36.67^{\circ} \mathrm{C}$. 


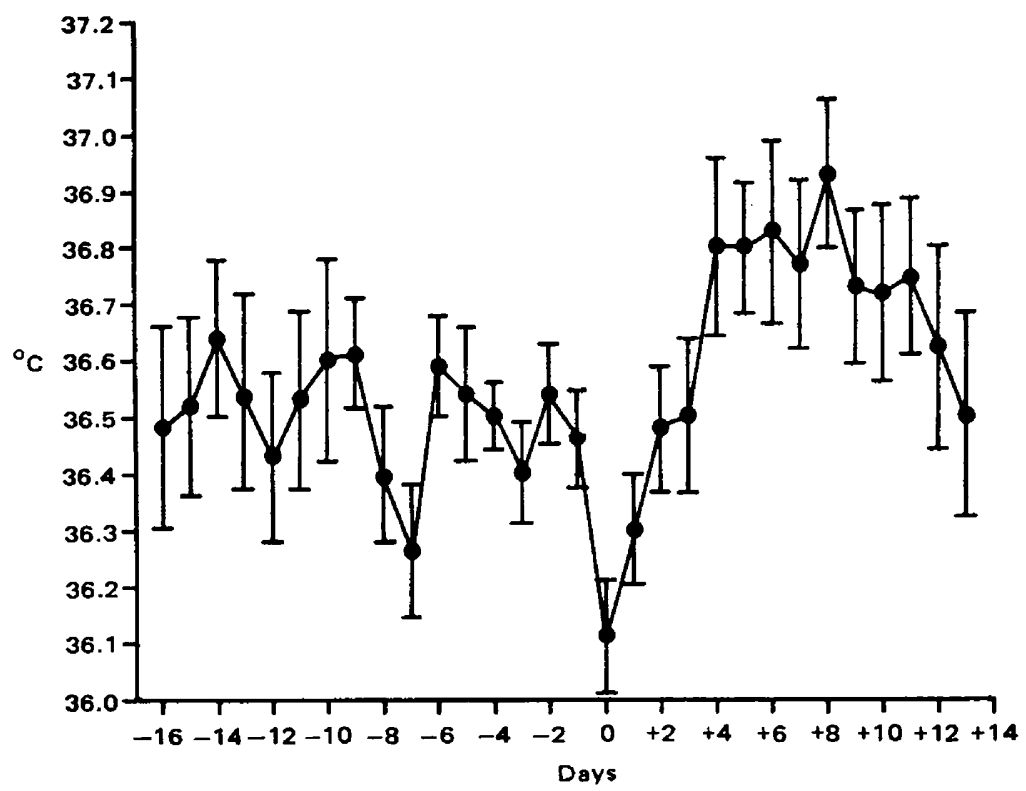

Text-fig. 1. Mean \pm S.E.M. nocturnal body temperature in 12 chimpanzee menstrual cycles normalized to the nadir (Day 0).

When the temperature nadirs and the subsequent $0 \cdot 3^{\circ} \mathrm{C}$ rises in 11 cycles were compared with the sexual swelling (the last day of maximal sexual swelling being designated Day 0 and the first day of swelling detumescence Day +1 ), it was found that $9 / 11$ nadirs occurred on Days $-1,0$ or +1 , indicating a close relationship between the temperature nadir and the last day of maximal sexual swelling. The mean interval between the temperature nadir and rise was $2 \cdot 7 \pm 0 \cdot 55$ (S.E.M.) days, but the range was $1-5$ days. The $0 \cdot 3^{\circ} \mathrm{C}$ temperature rise occurred between Days +1 and +5 and was therefore poorly correlated with the detumescence of the sexual swelling.

In three cycles (Text-fig. 2), the urinary oestrone and pregnanediol patterns and their temporal correlations with the sexual cycle and menses were determined and were found to be similar to those previously described in normal animals in this laboratory (Graham et al., 1972). In all three cycles a well-defined biphasic shift occurred, the nadir appearing on the day that urinary oestrone levels fell from the midcycle peak. This clearly indicates a temporal relationship between the midcycle urinary oestrone peak and the temperature nadir.

In two of these cycles (Text-figs $2 a$ and $2 b$ ) a pregnanediol elevation occurred on Day +2 and the $0.3^{\circ} \mathrm{C}$ temperature rise occurred on Days +3 and +4 respectively. However, in the other cycle (Textfig. 2c), the $0 \cdot 3^{\circ} \mathrm{C}$ temperature rise occurred on Day +2 , at least $48 \mathrm{~h}$ before a definite pregnanediol elevation was detectable.

In a fourth cycle (data not shown) there were several abnormal characteristics including a large but short-lived rise in pregnanediol $(1800 \mu \mathrm{g} /$ day $)$ and oestrone $(38 \mu \mathrm{g} /$ day $)$ on Days -3 and -2 , with a temperature nadir on Day -2. There was no pregnanediol rise after regression of the sexual swelling, and BBT did not exceed follicular levels.

\section{Discussion}

Using the radiotelemetry technique, we were able to demonstrate a clearly biphasic temperature shift in excess of $0.3^{\circ} \mathrm{C}$ at midcycle in 12 of 14 menstrual cycles. This pattern is similar to that demonstrated for temperature shifts in the rhesus monkey (Balin \& Wan, 1968). Attempts to demonstrate temperature shifts in the baboon (Hendrickx, Claborn, Laenger, Suhler \& Ware, 1967) and man 

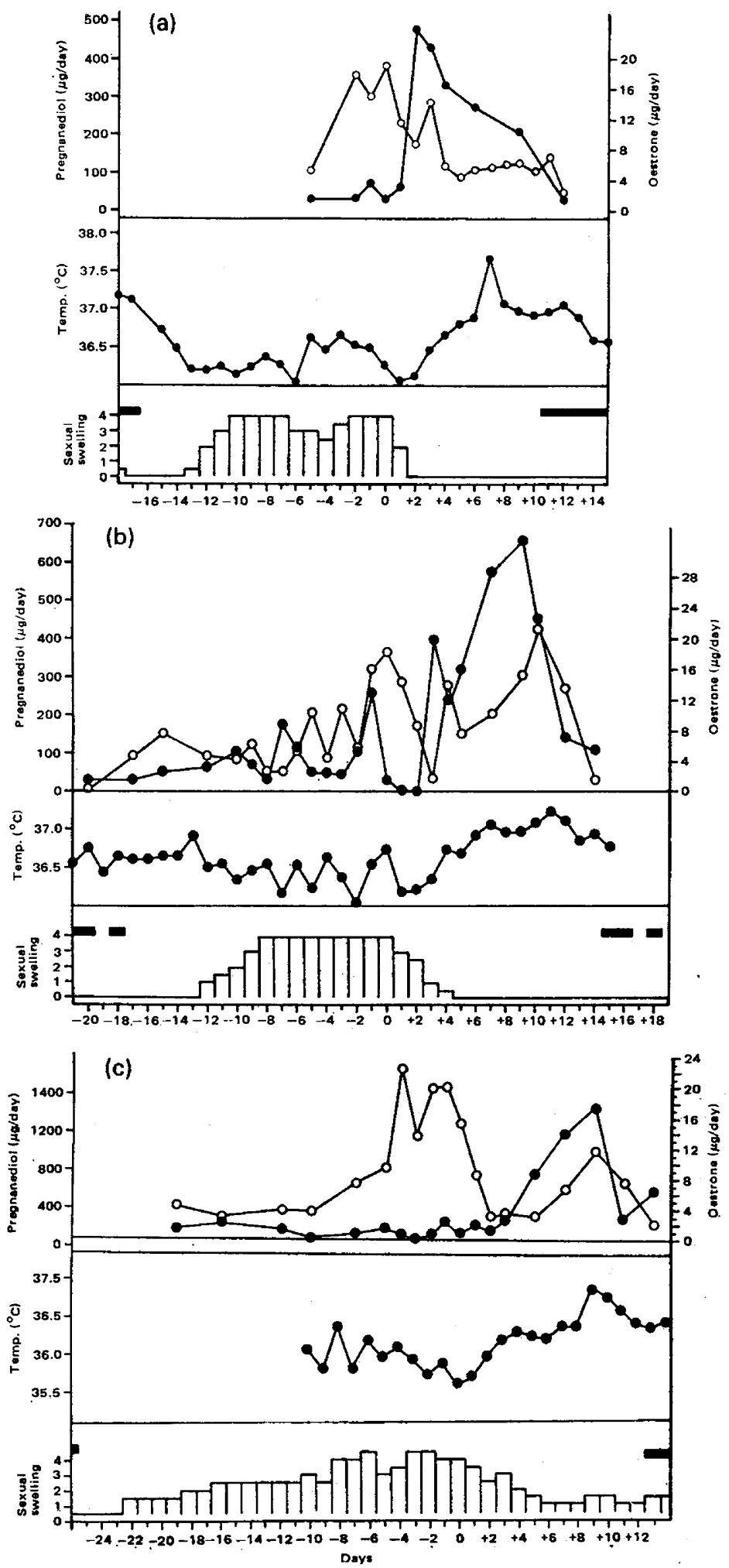
(Singer, Thomas \& Spector, 1964) using intravaginal telemetry have been much less successful, partly due to technical complications and frequent, apparently random, temperature excursions (Hendrickx et al., 1967).

Our data on the temporal relationship between the nadir, rise in BBT, and time of sexual swelling detumescence indicate a close association between the temperature nadir and detumescence of the sexual swelling. The interval between the nadir and the $0.3^{\circ} \mathrm{C}$ rise in BBT (and thus the rate of the temperature rise) was variable. The temperature rise was also poorly correlated with sexual swelling detumescence. Variability in the rate of temperature rise after the nadir has also been noted in women (Siegler \& Siegler, 1951). Because detumescence of the sexual swelling is closely correlated with the time of ovulation (Graham et al., 1972, 1973; Graham, 1973), we conclude that the nadir is a more accurate indicator of ovulation than is the temperature rise.

Falling temperatures were associated with increasing oestrone levels during the late follicular phase of two cycles. This effect has been described in women and attributed to a temperature-depressing effect of oestrogens (David \& Fugo, 1948; Israel \& Schneller, 1950). The temperature nadir in 3 normal cycles occurred the day after the midcycle oestrone peak, providing further evidence that the temperature nadir is an excellent parameter for identifying ovulation time in the chimpanzee. This observation that the oestrone peak precedes the nadir by 1 day correlates well with the recent finding of Morris, Underwood \& Easterling (1976) that in women the nadir usually occurs on the day of the $\mathrm{LH}$ peak.

The relationship between the significant temperature rise and the pregnanediol increment is not clear; the pregnanediol rise anticipated the temperature rise in 2 cycles (Text-figs $2 \mathrm{a}$ and $2 \mathrm{~b}$ ), followed it in a third cycle (Text-fig. 2c), and was abbreviated in a fourth cycle in which there was nevertheless a partial temperature shift.

The close temporal association of the temperature nadir with the midcycle urinary oestrone peak and the less precise correlation between the urinary levels of pregnanediol and the rise in BBT cast considerable doubt on the hypothesis that the temperature rise occurs solely in response to increased progesterone secretion in the chimpanzee. A similar lack of correlation in some human cycles has also been noted (Kalant et al., 1956). Other workers have suggested that the ratio of oestrogen to progesterone is of more importance in determining the BBT shift than is the progesterone level alone (Bergman, 1950). We have shown that the changing oestrogen/progesterone ratio is an important factor in the initiation and rate of detumescence of the sexual swelling in the chimpanzee (Graham et al., 1972), and it is therefore possible that individual differences in the oestrogen/progesterone ratio may account for the observed variability in the rate of midcycle temperature rise in this study.

The present results suggest that the temperature nadir is a more reliable indicator of the time of ovulation in the chimpanzee than is the luteal rise in temperature. If this conclusion also applies to women, it becomes of greater practical importance; a number of investigators have preferred some measure of rising temperature as a temporal parameter for analysis, because in some human cycles the nadir is difficult to define (Bergman, 1950; Israel \& Schneller, 1950; Siegler \& Siegler, 1951; Hartman, 1962). However, the nadir, whenever detectable, should provide the most reliable estimate of the fertile period.

This work was supported by Ford Foundation Grant 690-0645, and PHS Grant RR-00165 from the Animal Resources Branch of NIH. D.C.C. is the recipient of Career Research Development Award 1-K04-AM-70381 from The National Institute of Arthritis, Digestive and Metabolic Diseases.

Text-fig. 2. Urinary levels of oestrone ( $(0)$ and pregnanediol $(\bullet)$, nocturnal body temperature and sexual swelling in the menstrual cycle of the chimpanzee. The horizontal bars indicate days of menstruation. Day 0 is the last day of maximal swelling. (a) The first cycle of Chimpanzee A; (b) the 2 nd cycle of Chimpanzee A; (c) Chimpanzee B, in which the pregnanediol levels increased $48 \mathrm{~h}$ after the temperature rise. 


\section{References}

Balin, H. \& WaN, L.S. (1968) The significance of circadian rhythms in the search for the moment of ovulation. Fert. Steril. 19, 228-243.

Bergman, P. (1950) Sexual cycle, time of ovulation and endometrium and cervical mucus. Acta obstet. gynec. scand. 29, Suppl. 4, 1-139.

Buxton, L. \& ENGLE, E.T. (1950) Time of ovulation: a correlation between basal temperature, time of optimal fertility in women: studies on BBT, the appearance of the endometrium and the appearance of the ovary. Am. J. Obstet. Gynec. 60, 539-551.

Davis, M.E. \& Fugo, N.W. (1948) The cause of physiological basal temperature changes in women. J. clin. Endocr. Metab. 8, 330-563.

GrahaM, C.E. (1973) Chimpanzee endometrium and sexual swelling during menstrual cycle or hormone administration. Folia primat. 19, 458-468.

Graham, C.E., Collins, D.C., Robinson, H. \& Preedy, J.R.K. (1972) Urinary levels of estrogen and pregnanediol and plasma levels of progesterone during the menstrual cycle of the chimpanzee: relationship to the sexual swelling. Endocrinology 91, 13-24.

Graham, C.E., Keeling, M., Chapman, C., Cummins, L.B. \& HAYNIE, J. (1973) Method of endoscopy in the chimpanzee: relations of ovarian anatomy, endometrial histology and sexual swelling. Am. J. phys. Anthrop. 38, 211-216.

Hartman, C.G. (1962) Science and the Safe Period, p. 181. Williams and Wilkins, Baltimore.

Hendrickx, A.G., Claborn, L.D., Laenger, C.J., Suhler, S.A. \& WARE, R.W. (1967) Continuously telemetred vaginal temperature in the baboon. In The Baboon in Medical Research, Vol. II, pp. 419435. Ed. M. Vagtborg. University of Texas Press, Austin, Texas.
IsRael, S.L. \& SCHNeller, O. (1950) The thermogenic property of progesterone. Fert. Steril. 1, 53-64.

Kalant, N., Pattee, C.J., Simpson, G.W. \& Hendel.man, M. (1956) Timing of ovulation. Fert. Steril. 7, 5765.

MORRIS, N.M., UNDERWOOD, L.E. \& EAsterling, W. (1976) Temporal relationship between basal body temperature nadir and luteinizing hormone surge in normal women. Fert. Steril. 27, 780-783.

MORRISON, P. (1962) An analysis of body temperature in the chimpanzee. J. Mammal. 43, 166-171.

Preedy, J.R.K. \& Aitken, E.H. (1961) The determination of estrone, estradiol-17 $\beta$, and estriol in urine and plasma with column partition chromatography. J. biol. Chem. 236, 1300-1311.

Siegler, S.L. \& Siegler, A.M. (1951) Evaluation of basal body temperature and analysis of 1012 basal body temperature recordings. Fert. Steril. 2, 287301.

Singer, A., Thomas, R. \& Spector, B. (1964) An automatic system for the measurement and recording. of basal temperature in the human female. Fert. Steril. 15, 44-51.

TAUSK, M. \& DE VISSER, J. (1971) The effects of progesterone on body temperature. In Int. Encyc. Pharmacology and Therapeutics, Vol. I, Section 48. Pharmacology of the Endocrine System and Related Drugs: Progesterone, Progestational Drugs and Antifertility Agents, pp. 353-359. Ed. M. Tausk. Pergamon Press, New York.

WARnER, H. \& Graham, C.E. (1975) Temperature telemetry for continuous recording of body temperature in large, unrestrained animals. Int. Res. Commun. Syst., Med. Sci. 3, 214.

Received 8 July 1976 